\title{
FORMAR O HOMEM E O CIDADÃO: A IMPORTÂNCIA DO ENSINO DA LÍNGUA NACIONAL E DAS MATÉRIAS GEOGRAFIA E HISTÓRIA NAS PÁGINAS DA REVISTA DA ESCOLA NORMAL DE SÃO CARLOS (1916-1923)
}

\author{
Enéias Borges Dias ${ }^{1}$ \\ UNESP - Araraquara/SP
}

\section{RESUMO}

O presente artigo apresenta reflexões sobre o papel da imprensa educacional na propagação dos ideais republicanos de transformação da sociedade brasileira no período que compreende os anos de 1910 e 1920. A pesquisa teve como fonte documental a Revista da Escola Normal de São Carlos publicada e editada pelo corpo docente da Escola Normal Secundária de São Carlos entre os anos de 1916 a 1923 e destinada aos professores públicos. Dentre as temáticas abordadas pelo periódico o ensino da Língua Nacional, da Geografia e da História do Brasil foram amplamente veiculados, debatidos e propagandeados ao longo de suas páginas, durante seu "ciclo de vida", 1916 a 1923. Os temas abordados por essa publicação periódica contribuíram para a difusão de concepções e ideias sintonizadas com a problemática das transformações sociais educacionais em curso nos anos de 1910 e 1920.

Palavras-chave: Revistas de educação; História da Educação; escola normal; nacionalismo; São Carlos.

\section{TRAIN MAN AND CITIZEN: THE IMPORTANCE OF EDUCATION AND THE NATIONAL LANGUAGE OF GEOGRAPHY AND HISTORY IN THE MATTER OF PAGES REVISTA DA ESCOLA NORMAL DE SÃO CARLOS (1916-1923)}

\begin{abstract}
This article presents reflections on the educational role of the press in the spread of republican ideals of transformation of Brazilian society in the period comprising the years 1910 and 1920. The research was based on the Revista da Escola Normal de São Carlos document published and edited by the faculty of the Normal School of San Carlos between 1923 to 1916 years for public school teachers. Among the topics addressed by the mainstream of the National Language, Geography and History of Brazil were widely disseminated, discussed and advertised throughout its pages during its "life cycle" of 19161923. The issues addressed by the periodic publication contributed to the dissemination of concepts and ideas in tune with the problems of social change in education course in the years 1910 and 1920.
\end{abstract}

Keywords: education journals, History of Education; normal school; nationalism; São Carlos.

A Revista da Escola Normal de São Carlos, editada pelo corpo docente da Escola Normal de São Carlos, constitui o objeto central desse artigo, voltado à compreensão do estudo e análise de temas considerados pelos intelectuais das décadas de 1910 e 1920 como imprescindíveis à formação da nação brasileira. Dentre as temáticas abordadas pelo periódico o ensino da Língua Nacional, da Geografia e da História do Brasil foram amplamente veiculados, debatidos e propagandeados ao longo de suas páginas, durante seu "ciclo de vida", 1916 a 1923. 
Considerada uma das primeiras revistas de educação e ensino mantida, editada e distribuída por professores normalistas do interior paulista na Primeira República, a Revista publicou artigos inéditos, cujos autores vinculavam-se à própria Escola Normal de São Carlos e demais estabelecimentos de ensino público do Estado, e exerciam diferentes funções na carreira do magistério: professores de escolas normais, professores primários, diretores de escolas, entre outros. Preocupados com os rumos da Nação e da República, empenhados em inovar o ensino praticado nas escolas públicas, os autores debruçaram-se sobre os mais variados assuntos: pedagogia, filosofia, ciência, métodos e processos de ensino, nacionalismo, êxodo rural, higiene escolar e formação de professores.

O "ciclo de vida" da Revista transcorreu numa conjuntura crucial e fremente da formação social brasileira, quando se tornou visível, pelo menos para as vanguardas políticas e intelectuais, a necessidade "republicanizar a república". Nessa conjuntura de urgência, um momento rico de reflexões, projetos, ideias sobre os rumos da sociedade brasileira e ocidental, emergiram os mais diversos movimentos políticos, sociais e culturais a reivindicarem para si a incumbência de regeneração e avivamento da nacionalidade pela via da educação popular. E como não poderia deixar de ser, tal conjuntura e seus acontecimentos foram objetos de análises, discussões e propostas nas páginas da Revista.

A Revista publicou inúmeros artigos sobre a obrigatoriedade do ensino da Língua Nacional e valorização do ensino da História e da Geografia do Brasil. Nos artigos havia uma preocupação permanente: fazer por meio da educação com que nacionais e imigrantes se identificassem, criassem vínculos com a "Pátria Mãe", conhecessem a geografia e a história e valorizassem as "coisas nacionais". Em suma: promover os valores cívicos, levar o povo a amar o país, altear o povo e a terra, difundir o idioma nacional, eram as palavras de ordem não só nas páginas da Revista como também nos meios os mais variados do país. Nos círculos políticos e intelectuais locais e nacionais havia um consenso acerca da urgência da construção da identidade da nação e de um regime representativo democrático de modo a colocar o Brasil no rumo das nações europeias e dos Estados Unidos da América do Norte.

Como observou Nagle em "Introdução da Escola Nova no Brasil (Antecedentes)" (1964, p.98):

\footnotetext{
Desde o começo do século ganha importância nuclear a formação cívica e moral, como base do soerguimento de amplos quadros da nacionalidade. Ideal de formação que se prende ao ambiente de pessimismo que dominou o país pouco depois da proclamação da República, significando de resto o desgaste da ilusão da República-Educadora. [...] De qualquer maneira, no quadro típico dessa época se privilegia a dimensão cívico nacionalista do processo de educação escolar. As tendências remodeladoras introduzem-se nesse quadro, quando muito, como elementos secundários, auxiliares desse núcleo básico.
}

Ana Luiza Martins, em "Modelando gerações: revistas pedagógicas", capítulo do livro Imprensa e práticas culturais em tempos da República: São Paulo (1890-1922) (2001) considerou ser frequente encontrar nas revistas pedagógicas artigos relacionados com a temática da moral, civismo e religião. De fato, no clima de nacionalismo exaltado, atribuía-se ao ensino da língua oficial a função de conferir coesão e unicidade de sentimentos, isto é, o "amor pela pátria". Para essa perspectiva otimista ao ensino da disciplina Geografia caberia valorizar as belezas e as riquezas do país, ao ensino de História demonstrar as novas gerações os feitos dos heróis nacionais e dos cidadãos exemplares. 
Carlos da Silveira e Dagoberto Salles, membros da "Liga Nacionalista de São Paulo", Ezequiel de Moraes Leme, Waldomiro Caleiro, Teodorico de Camargo, Atugasmim Médici, Elisário Fernandes de Araújo, João Augusto de Toledo, Mariano de Oliveira, entre outros professores, em palestras, conferências e artigos buscaram retratar o Brasil em suas especificidades, apontando seus problemas e sugerindo soluções. Temas como a erradicação do analfabetismo, a participação eleitoral do cidadão, a gente brasileira, as belezas naturais do Brasil, à educação cívica, considerada elemento fundamental para o soerguimento moral da nação e para a cultura do patriotismo, o escotismo como fator de educação do caráter e de defesa da pátria foram enfatizados.

Por exemplo, em "Os ideais nacionais e as escolas elementares", João Augusto de Toledo ressaltava a importância do ensino cívico na formação cívico moral das crianças: "Na alma da criança modela-se a conduta do homem. Hábitos de camaradagem, de polidez, de asseio, de disciplina, de discrição, de iniciativa de economia, de tolerância, de estudo, de trabalho de honestidade ali se formam" (1920, p.7). Ou como apregoara anteriormente, Mario Natividade no "Discurso pronunciado na festa inaugural da Sociedade de Estudos e Conferências", no dia 9 de setembro de 1916:

Meus senhores - Em meio dos descalabros que desgraçadamente vão pela nossa vida nacional, através da crise financeira e da crise moral que avassalam o país, já se percebe um movimento vago, mas alentador, de regeneração e ressurgimento. Sente-se um como despertar de consciências esquecidas e um como reviver de liberdades apagadas. (1917, p.24)

Defensor ardoroso da escola primária como via de transformação social e culturas, Carlos da Silveira traduziu e publicou nos fascículos 11 e 12, o programa escolar praticado na Bélgica. No programa, segundo ele, a ser adotado pelos brasileiros, eram ressaltados assuntos como "educação individual" — higiene, prudência, dignidade, disciplina, economia, trabalho, perseverança e instrução; "educação altruísta" — harmonia social e amor à natureza, liberdade de opinião; "educação nacional" — soberania nacional, poderes da nação, defesa do território, liberdade de culto, imprensa, associação e reunião e o amor pela pátria.

Traduzido sob o título "Do papel educativo da escola primária", o programa priorizava o estudo da Língua Materna, História e Geografia. Escrevia Carlos Silveira: "Se este meu trabalho - tradução na sua quase totalidade - não é o que se costuma chamar de uma novidade, julgo, todavia que poderá prestar serviços não de todo insignificantes aos novos lides do magistério" (1921, p.21).

Era nessa conjuntura de ideias inovadoras e de planos de soerguimento moral da nação que os autores debatem nas páginas da Revista a erradicação do analfabetismo, a participação eleitoral do cidadão, a ênfase na educação cívica, a cultura do patriotismo, a importância da escola primária. Em resumo: como explica Ilíada Pires da Silva, em "Educadores paulistas: regeneração social, República e nação" (1999, p.128), o projeto republicano sugeria não apenas uma mudança parcial: "mas sim um projeto cultural que atravessa a sociedade completamente" 2

\section{A Língua Nacional}

Em A Revista do Brasil: um diagnóstico para a (n)ação, Tania Regina de Luca (1999), especialmente no capítulo "Língua: edificação da cultura nacional", ressaltou a importância atribuída pelos intelectuais do apreço ao ensino e uso da língua como fator de 
afirmação da identidade e soberania nacionais. Sem dúvida, a defesa do ensino da Língua Nacional foi uma das preocupações recorrentes nas páginas da Revista.

Em "A língua pátria e a unidade nacional”, de Carlos da Silveira (1917, p.65), a língua é considera elemento essencial nos países novos como os da América Latina: "a comunhão de linguagem facilita a troca de ideias e a comunicação dos espíritos, torna a simpatia mais fácil e mais forte, o conjunto mais coerente e, por conseguinte, favorece o sentimento de Pátria". Definida como conjunto de sinais - falados, ouvidos, escritos e lidos - a língua era a expressão de sentimento e pensamento de um povo. Para o autor, a evolução de um grupo social seria apreciada pela linguagem utilizada: "cada agrupamento humano é superior ou inferior em mentalidade conforme a excelência ou não da língua que fala".

Pela clareza do francês avaliamos a finura do espírito daquele povo; a tonalidade variadíssima do alemão é indício da profundeza da mente germânica; a língua inglesa revela-nos o espírito prático do anglo-saxão; a sonoridade do italiano dá bem a medida da aptidão artística dos nascidos na terra de Dante, Leonardo da Vinci, Jose Verdi e tantos outros prediletos das filhas de Mnemósina. Em resumo, língua pobre ou rica, clara ou obscura, elegante ou desataviada equivalem a espíritos com esses atributos. (idem, p.67)

Em "A escola brasileira", João Augusto de Toledo, defendia ideias análogas, ou seja, uso da língua oficial como instrumento de união e formação do cidadão patriota:

A língua falada pelo povo é o primeiro de sua escola. É o primeiro e mais importante, porque é fator enérgico de nacionalização e um laço estreito de solidariedade. Os que falam a mesma língua comungam os mesmo sentimentos e têm os mesmo ideais e as mesmas tradições. $(1917$, p.79)

Fator de unidade de sentimento e pensamento, o ensino e o uso da língua nacional trariam contribuição decisiva na construção da identidade nacional, afirmava o autor: "Em um país de imigração, como o nosso, ela deverá merecer do professor o melhor cuidado, porque é um recurso poderoso do qual podemos lançar mão para assimilar os estrangeiros" (idem). No seu ponto de vista, os "aglomerados estrangeiros" 3 , quase sempre localizados em regiões longínquas do território nacional e, portanto, distantes dos poderes públicos, partilhavam de uma mesma situação: "não havendo escolas nossas, fundam eles as suas; recebem de além-atlântico todos os objetos necessários e subvenção remunerada".

Estudam sua língua, a história e geografia de sua pátria, conservam suas tradições e seus costumes, vivem em nossa terra como se vivem na sua, sempre estrangeiros, legando a seus filhos a mesma alma de seus avós. Este fato, profundamente alarmante, só de há pouco tempo para cá conseguiu chamar nossa atenção, sem que tenhamos, entretanto, procurado dar remédio a essa gravíssima anomalia. (idem)

Carlos da Silveira, em outro artigo, "A língua pátria e a unidade nacional” defendia argumentos de igual teor:

É ela, a língua o vínculo que prende e estreita solidamente as várias peças do organismo nacional. Destruído esse liame, os elementos desagregam. É ela que mantém a nação coesa e forte. É com ela que se 
transmite de geração a geração esse legado de poesias, romances, lendas, tradições, que constituem o esplêndido material para o estudo da alma popular nos mais recônditos escaninhos. $(1917$, p.74)

Esse tipo de argumentação visava a dois objetivos: neutralizar o uso desagregador das línguas estrangeiras e unir o povo pelos laços de uma mesma língua e cultura. A questão gramatical ou filológica parece não ser a grande preocupação dos autores, o incômodo de fato era a existência de culturas estrangeiras no país. Tornar obrigatório o ensino da Língua Portuguesa era o meio de combater os "efeitos venenosos", "o perigo estrangeiro".

Os núcleos de imigrantes, isolados na vastidão do território, constituem verdadeiros postos avançados de quiçá pretendida conquista. A solução de continuidade que tais núcleos geram no nosso povo, não ainda bastante coeso para assimilá-los, é um perigo que só pode ser conjurado pela mobilização das energias computáveis: e entre estas apresenta-se, em primeira linha, o ensino inteligente da língua nacional, o seu cultivo aprofundado e largamente generalizado nas escolas de todos os graus e em toda a parte. (SILVEIRA, 1917, p.74).

Em outro artigo, o "Culto cívico", o mesmo Carlos da Silveira, ao expressar as principais ideias da Liga Nacionalista de São Paulo indicava como uma das prioridades dessa associação, a difusão da língua oficial.

Falai bem a língua nacional!

País de imigração, a língua nacional bem falada e conhecida é um poderosíssimo instrumento de assimilação. Cultivemos com excepcional carinho a língua de nossa terra, em toda a vastidão do território pátrio, na imprensa e no livro, na conferência e na palestra, em público ou no ambiente familiar: é isso a defesa pacífica do Brasil. Há uma resistência que se opõe, são as armas nas mãos, destruindo-se o inimigo no calor das batalhas, mas também uma defesa menos rumorosa, muito mais modesta no agir, mais valiosa, porém, e que faz quotidianamente, minuto a minuto, em todos os recantos da Pátria, fortalecendo-se os vínculos nacionais, agregando-se os elementos estranhos, extirpando as formações prejudiciais. (1919, p.18-19).

Como se nota nos trechos citados havia uma consonância com os programas das ligas Nacionalista de São Paulo e de Defesa Nacional; de fato, ambas as ligas defendiam a implantação de escolas primárias nos núcleos coloniais e a obrigatoriedade do ensino da Língua Portuguesa. De modo geral, no período, especialmente a Reforma de 1920 executada por Antonio de Sampaio Dória, intensificou-se em São Paulo o controle das "escolas estrangeiras", as quais foram submetidas a uma supervisão mais rigorosa sendo obrigadas a assumir um compromisso por escrito, comprometendo-se a respeitar os feriados nacionais, promover ensino do Português (por professor brasileiro ou português nato), o ensino de Geografia e História do Brasil (por professor brasileiro nato), o ensino dos hinos nacionais, e respeitar a proibição do ensino de língua estrangeira para crianças menores de dez anos e o acesso das autoridades do ensino aos estabelecimentos. 


\section{Geografia e História do Brasil: "nossas riquezas, nossos heróis"}

Mas, como organizar um país com tamanha dimensão territorial e diversidade étnica e cultural? Essa parece ser a questão para a qual convergiam as preocupações dos círculos intelectuais e políticos nas décadas de 1910 e 1920 e como resposta atribuiu-se a escola primária, como já dissemos um papel primordial.

Se no programa da Liga Nacionalista de São Paulo, a língua era um instrumento de defesa e abrasileiramento, a língua em si mesma não era considerada suficiente para insuflar "o amor à pátria" e a "união entre os brasileiros", era preciso ir além, e promover o ensino da Geografia e da História do Brasil. A valorização das riquezas naturais do Brasil e o culto dos heróis, segundo Tania Regina de Luca (1999) demonstravam a procura dos "verdadeiros valores" nacionais. Para os articulistas da Revista caberia à escola e ao ensino valorizar tudo aquilo que o país tinha de melhor.

Conforme Jorge Nagle, em Educação e sociedade na Primeira República, as atividades exteriores à sala de aula refletiam a insuficiência pedagógica da escola primária:

Contudo, seja no caso da Geografia e da História Pátria seja no caso da Instrução Cívica, não se pode deixar de mencionar esse obstáculo: ausências de livros didáticos apropriados ao ensino dessas disciplinas e elaborados de acordo com as exigências do nacionalismo da década dos vinte. De qualquer modo, nesse decênio começa a se operar uma mudança que deve ser ressaltada: a tendência é substituir o conteúdo "patriótico", puramente sentimental e de teor idealista de nacionalismo por um outro conteúdo que se baseia mais no "conhecimento" que se deve ter da terra e da gente brasileira. (1976, p.232).

Em “A Geografia e o seu ensino", Ezequiel de Moraes Leme, expressava a importância atribuída a essa matéria nas escolas primárias e secundárias, para ele, o ensino deveria ir além da mera descrição do meio, de modo a fazer o aluno "conhecer", "sentir", "saber a utilidade" e "valorizar" o país.

É necessário que a renascença da ciência geográfica repercuta no Brasil, inspirando mais um pouco de amor aos que tem por dever ensiná-la nos institutos secundários (é do ensino secundário que me ocupo), de modo a porem de lado o mero ensino descritivo, sem apoio e base científica, e a darem a Geografia o papel que lhe compete de ciência explicativa, na mais larga acepção do termo. Ensinem eles ser a Geografia uma ciência de observação e de raciocínio, a ciência das relações entre Terra e o Homem, que procura fazer compreender a imensidade do Grande Oceano, a exuberância das florestas virgens americanas, os costumes dos negros africanos. Mostrem eles como, pela constituição geológica do solo, pelas formas do relevo e pelo clima, essa ciência explica o regime dos cursos da água, as formas vegetais, os animais e a vida humana; como ensina até que ponto o homem é escravo das forças do universo e o prisioneiro da Terra, mas também, como pode lutar e reagir; como faz compreender a dependência estreita e recíproca que há entre a Terra e o homem, revelando assim o harmonioso encadeamento que preside a vida universal. (1919, p.24).

Os artigos sobre a importância do ensino de Geografia representavam o território nacional de modo maravilhoso: diversidade de animais, riquezas vegetais, rios, florestas, 
pântanos, paisagens maravilhosas, solo fértil e clima bom. No entanto, tal grandiosidade não era devidamente valorizada pelos habitantes locais e tampouco utilizada de forma correta, podendo despertar a cobiça estrangeira. No artigo anteriormente citado, "A escola brasileira", João Augusto de Toledo, originariamente, em conferência na Escola Normal em 13 de outubro de 1917, escrevia:

$\mathrm{Na}$ escola primária, a Geografia-Pátria é disciplina da mais alta relevância. Ela compreende o estudo da terra, do homem, da flora, da fauna e também do céu. $O$ ponto de vista largamente utilitário impõe-se aqui. Largamente utilitário, disse, porque ele deverá aproveitar aos interesses materiais da agricultura, da indústria e do comércio, como à formação moral do educando. Sejam postas de lado, sem nenhum receio, as preocupações de mera ilustração. Não nos interessam mais as vastas nomenclaturas de lagos, portos, rios, cidades; importa-nos saber quais os benefícios que estes acidentes nos podem prestar. $(1917$, p.80).

Portanto, a Geografia apresentaria aos alunos as riquezas nacionais, mostraria os meios de transporte, as cidades e as diversidades regionais.

Virão povoar o cérebro das crianças de conhecimentos úteis e lhes abrirão a perspectiva de um futuro feliz. Aos pouco irão se afeiçoando ao meio e, logo, tudo quanto disser a respeito do país ser-lhes-á familiar. As riquezas da terra, os encantos naturais, a beleza do céu, passarão, como imagens, a constituir pedaços da alma infantil que por isso far-se-á uma alma brasileira. Assim a Geografia compreendendo até os elementos das ciências naturais, deverá ser ensinada na escola primária. (TOLEDO, 1917, p.80-1).

Para o mesmo João Toledo, ao ensino da Língua Nacional e da Geografia acrescentar-se-ia o ensino de História, e então, despertaria em definitivo, o sentimento de afinidade com a "terra mãe", levando o aluno a partilhar da "alma nacional".

O concurso da História virá completar a obra da Geografia. E a ela cabe um papel decisivo que ainda não foi bem compreendido por todos os professores. Correm por ai compêndios de História que atestam estreiteza de vistas e desconhecimento de sua função educativa no ensino primário. Exposições incolores de fatos administrativos, narrativas glaciais de batalhas, listas de nomes e de datas que não despertam interesse, não prendem atenção, não emocionam e nem fornecem aptidões para crítica que oriente conduta. É a história pensada, e mal pensada, e nunca a história sentida, fortemente sentida, única que as classes infantis comportam. (p.81).

\section{Os exemplos de conduta e ideais}

Ao ensino de História caberia transmitir os conhecimentos sobre a administração do Estado, as tradições herdadas dos antepassados, a literatura, as artes e os costumes do povo. E o estudo das biografias dos heróis nacionais e cidadãos exemplares seria o primeiro passo para tornar o ensino agradável às crianças. 
No primeiro ano de estudo, os contos de fadas, as anedotas escolhidas servem de preparação; depois será dada, em linhas gerais, a vida de alguns de nossos heróis, cujos retratos mostraremos as crianças para que melhor os conheçam. Estas lições orais têm a vantagem de estabelecer, entre mestres e alunos, diálogos interessantes onde à linguagem se corrige e se apura. O professor estudando a vida de nossos maiores, em seus atos de meninos, em seus feitos de homens, terá o cuidado de examinar apenas as passagens mais salientes, mais sugestivas e por isso, mais compreensíveis. A partir do segundo ano, o ensino irá progressivamente aumentando sua amplitude: os maiores representantes do país na administração, na guerra, na literatura, nas artes, irão aparecendo aos poucos, acompanhando-se, quando possível, de quadros explicativos, as ações desenvolvidas por cada um. Ao finalizar o segundo semestre do último ano, dar-se-á por concluído o estudo feito por meio de biografias; e, em síntese rápida, os fatos essenciais serão apresentados, em ordem cronológica. (TOLEDO, 1917, p. 81).

Os heróis e cidadãos exemplares serviriam de modelos de dignidade e conduta, assim,

[...] os filhos dos estrangeiros terão a mente povoada das mesmas ideias que povoam as nossas; o coração formar-se-á na mesma lareira de emoções; seus lábios falarão nossa língua; terão eles mesmas aspirações nossas; em uma palavra serão brasileiros (idem).

Com isso pretendia-se promover o soerguimento moral da nação por meio das apresentações dos grandes nomes da história pátria: Tiradentes representava o homem do povo simples e humilde cuja morte fora semelhante à de Cristo, e dera a própria vida pelos ideais de liberdade e igualdade; Duque de Caxias, o guerreiro responsável por manter a ordem e a união nacional, demonstrando um povo forte, que sabe negociar a paz e lutar quando for preciso; D. Pedro II, o homem nobre, honrado e bondoso; Campos Salles, o administrador que salvou o país do colapso financeiro; e Rui Barbosa, o grande orador e civilista. $\mathrm{O}$ intuito era o de resgatar vidas exemplares um tanto esquecidas pela memória nacional e ao mesmo tempo resgatar as raízes da República, regime político providencial, o qual aparecia como antigo ideal e velha aspiração, o que poderia ser comprovado pelo conhecimento das biografias de homens célebres, cujos sacrifícios em prol da nação eram visíveis. Em resumo: era necessário valorizar o ensino da Geografia, História e da Língua Nacional, difundir o sentimento patriótico, abrasileirar os nacionais e os imigrantes pelo culto cívico da personalidade.

\section{Referências:}

FERLINI, Vera Lucia Amaral; FILLIPPINI, Elizabeth. Os núcleos coloniais paulistas em perspectiva historiográfica. Revista Brasileira de História. São Paulo, v.13, n. 25-26, p.147-166, ago., 1993.

LEME, Ezequiel de Moraes. A Geografia e seu ensino. Revista da Escola Normal de São Carlos, Propriedade e redação do Corpo Docente, ano 4, n.7, p. 22-25, dez., 1919. 
LUCA, Tania Regina de. A Revista do Brasil: um diagnóstico para a (n) ação. São Paulo: Ed. Unesp, 1999.

MARTINS, Ana Luiza. Modelando gerações: revistas pedagógicas. In: Imprensa e práticas culturais em tempos da República: São Paulo (1890-1922). São Paulo: EDUSP: FAPESP: Imprensa Oficial do Estado, 2001, p.304-323.

NAGLE, Jorge. Educação e sociedade na Primeira República. São Paulo: EPU, 1976.

Introdução da Escola Nova no Brasil (Antecedentes). Boletim da cadeira de Teoria Geral da Educação, Araraquara, FFCL, ano 1, 1964.

NATIVIDADE, Mario. Discurso pronunciado na festa inaugural da Sociedade de Estudos e Conferencias, no dia 9 de setembro de 1916. Revista da Escola Normal de São Carlos, Propriedade e redação do Corpo Docente, ano 1, n.2, p.13-17, jun., 1917

SILVA, Ilíada Pires da. Associação Beneficente do Professorado Público do Estado de São Paulo: a constituição de um perfil sócio-cultural docente - 1901-1910. São Paulo, 2004. Tese (Doutorado em Educação). Faculdade de Educação - Universidade de São Paulo.

Educadores paulistas: regeneração social, República e nação. In: FERREIRA, Antonio Celso; DE LUCA, Tania Regina \& IOKOI, Zilda Grícoli (Orgs.). Encontros com a história: percursos históricos e historiográficos de São Paulo. São Paulo: UNESP, 1999.

SILVEIRA, Carlos da. A língua pátria e a unidade nacional. Revista da Escola Normal de São Carlos, Propriedade e redação do Corpo Docente, ano 2, n.3, p.62-76, dez., 1917.

Culto cívico: conferência realizada no Politeama de Araraquara, no dia 7 de setembro de 1918, por incumbência da Liga Nacionalista. Revista da Escola Normal de São Carlos, Propriedade e redação do Corpo Docente, ano 4, n.7, p.3-21, dez., 1919

. Do papel educativo da escola primária. Revista da Escola Normal de São Carlos, Propriedade e redação do Corpo Docente, ano 6, n. 11, p.7-21, dez., 1921.

TOLEDO, João Augusto de. A escola brasileira. Revista da Escola Normal de São Carlos, Propriedade e redação do Corpo Docente, ano 2, n.3, p.77-83, dez., 1917.

Os ideais nacionais e as escolas elementares. Revista da Escola Normal de São Carlos, Propriedade e redação do Corpo Docente, ano 4, n.8, p.3-20, jun., 1920.

Notas:

\footnotetext{
${ }^{1}$ Mestre em Educação Escolar pela Universidade Estadual Paulista Júlio de Mesquita Filho- UNESP Campus de Araraquara/SP (2009); graduado em História pela Universidade Estadual Paulista Júlio de Mesquita Filho - UNESP - Campus de Assis/SP (2001). Atualmente é professor titular de cargo - PEB - II História - Secretaria da Educação do Estado de São Paulo e da Escola SESI-Matão/SP - Centro Educacional -146. eneiasmarilia@yahoo.com.br
} 
${ }^{2}$ Sobre o assunto ver também Silva (2004).

${ }^{3}$ João Augusto de Toledo refere-se aos "núcleos coloniais" que surgem em meados do século XIX, no âmbito da política de incentivo à imigração europeia ao Brasil. Tratava-se de importantes agrupamentos humanos distribuídos em pequenos lotes de terras estabelecidos pelo Estado e oferecidos aos imigrantes que chegavam da Europa com o intuito de promover a fixação do homem ao campo e o povoamento da nação, principalmente de regiões desabitadas. Os primeiros núcleos foram estabelecidos em regiões de difícil acesso e pouca povoação, devido dificuldades para o escoamento das produções, muitas dessas propriedades fracassaram. Em São Paulo por sua vez, a implantação dos núcleos coloniais ocorreu em diversos locais do interior do estado, como Campinas, São Bernardo do Campo, Guaratinguetá, Ibitinga, Iguape, Mogi das Cruzes e Ribeirão Preto, entre outros. A partir do final do século XIX os núcleos coloniais que surgem em São Paulo, ao contrário de outras regiões do país, não visavam o povoamento da região, mas sim propiciar reservas de mãos-de-obra para lavoura de café no momento da colheita, é o que afirmam os pesquisadores Vera Lúcia Amaral Ferlini e Elizabeth Fellippini (1993). Entre os anos de 1885 e 1911 foram criados 25 núcleos coloniais no estado de São Paulo, muitos desses estabelecidos por iniciativa particular como é o caso do Núcleo Colonial Gavião Peixoto. Mais informações consultar: FERLINI \& FELLIPPINI (2003) e ARQUIVO PÚBLICO DO ESTADO DE SÃO PAULO. Imigração em São Paulo: núcleos. Disponível em: < http://www.arquivoestado.sp.gov.br/imigracao/nucleos.php>. Acesso em 02/07/2012

Recebido em

outubro/2011

Aprovado em julho/2012 